\title{
Acoustic relaxation of some lead niobium tellurite glasses
}

\author{
M S GAAFAR ${ }^{1, a, *}$ and Y A AZZAM ${ }^{2, a}$ \\ ${ }^{1}$ Ultrasonic Department, National Institute for Standards, Giza 12211, Egypt \\ ${ }^{2}$ National Research Institute of Astronomy \& Geophysics, Helwan, Cairo 10104, Egypt \\ ${ }^{a}$ Current address: College of Science, Majmaah University, Zulfi 11932, Saudi Arabia
}

MS received 17 June 2013; revised 18 April 2014

\begin{abstract}
The longitudinal ultrasonic attenuation in $x \mathrm{Nb}_{2} \mathrm{O}_{5}-(1-x) \mathrm{TeO}_{2}, 0.1 \mathrm{PbO}-x \mathrm{Nb}_{2} \mathrm{O}_{5}-(0.9-x) \mathrm{TeO}_{2}$ and $0.2 \mathrm{PbO}-x \mathrm{Nb}_{2} \mathrm{O}_{5}-(0.8-x) \mathrm{TeO}_{2}$ tellurite glass systems was measured using the pulse echo technique at ultrasonic frequencies 2, 4, 6 and $8 \mathrm{MHz}$ in the temperature range from 150 to $300 \mathrm{~K}$. The absorption curves showed the presence of well-defined broad peaks at various temperatures depending upon the glass composition and operating frequency. The maximum peaks move to higher temperatures with the increase of operating frequency, indicating the presence of some kind of relaxation process. This process has been described as a thermally activated relaxation process, which happens when ultrasonic waves disturb the equilibrium of an atom vibrating in a double-well potential in the glass network structure. Results proved that the average activation energy of the process depends mainly on the modifier content. This dependence was analysed in terms of the loss of standard linear solid type, with low dispersion and a broad distribution of Arrhenius-type relaxation with temperature-independent relaxation strength. The experimental acoustic activation energy has been quantitatively analysed in terms of the number of loss centres (number of oxygen atoms that vibrate in the double-well potential).
\end{abstract}

Keywords. Tellurite glasses; ultrasonic velocity; activation energy; deformation potential.

\section{Introduction}

Tellurite-based glasses have been the subject of both academic and technological interest due to the fact that, they possess high refractive indices with low dispersion values, low tendency to crystallize, good chemical resistance, good semiconducting properties and low melting points. ${ }^{1-6}$ To our knowledge, the structure and properties of oxide glasses are strongly dependent on the nature and concentration of the constituent oxides. Therefore, the modifier atoms cause transformations in the basic structural units, namely $\mathrm{TeO}_{4}$ trigonal bipyramid (tbp) and $\mathrm{TeO}_{3}$ trigonal pyramid (tp) units, both of which have a lone pair of electrons occupying one of the equatorial positions.

The longitudinal ultrasonic attenuation in ternary $80 \mathrm{TeO}_{2}-(20-x) \mathrm{WO}_{3}-x \mathrm{~K}_{2} \mathrm{O}$ tellurite glass systems was measured by Gaafar and Sidkey ${ }^{7}$ using the pulse echo technique at ultrasonic frequencies 2, 4, 6 and $8 \mathrm{MHz}$ in the temperature range from 160 to $300 \mathrm{~K}$. The absorption spectra showed the presence of well-defined broad peaks at various temperatures depending upon the glass network structure and the operating frequency. The authors showed that the mean activation energy is strongly dependent on the modifier content.

Gaafar et $a l^{8}$ have introduced an artificial neural network (ANN) technique to simulate and predict important parameters such as density, longitudinal and shear ultrasonic velocities and elastic moduli (longitudinal and shear moduli) for more than 30 glass compositions. The authors

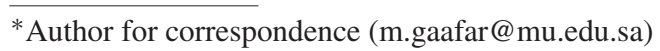

showed that the predicted results were found to be in good agreement with those experimentally measured parameters. Later they have used the ANN model to predict the acoustic properties of some new tellurite glasses. For this purpose, four glass systems $x \mathrm{Nb}_{2} \mathrm{O}_{5}-(1-x) \mathrm{TeO}_{2}, 0.1 \mathrm{PbO}-$ $x \mathrm{Nb}_{2} \mathrm{O}_{5}-(0.9-x) \mathrm{TeO}_{2}, 0.2 \mathrm{PbO}-x \mathrm{Nb}_{2} \mathrm{O}_{5}-(0.8-x) \mathrm{TeO}_{2}$ and $0.05 \mathrm{Bi}_{2} \mathrm{O}_{3}-x \mathrm{Nb}_{2} \mathrm{O}_{5}-(0.95-x)$ were prepared using the melt quenching technique. The results indicated that the incorporation of $\mathrm{Nb}_{2} \mathrm{O}_{5}$ as a network modifier provides oxygen ions to transform $\left[\mathrm{TeO}_{4}\right]$ tbps into $\left[\mathrm{TeO}_{3}\right]$ bps.

\section{Aim of the work}

In the present paper, we have studied the variation of ultrasonic attenuation in three different glass series $x \mathrm{Nb}_{2} \mathrm{O}_{5}-(1-x) \mathrm{TeO}_{2}, 0.1 \mathrm{PbO}-x \mathrm{Nb}_{2} \mathrm{O}_{5}-(0.9-x) \mathrm{TeO}_{2}$ and $0.2 \mathrm{PbO}-x \mathrm{Nb}_{2} \mathrm{O}_{5}-(0.8-x) \mathrm{TeO}_{2}$ with different $\mathrm{Nb}_{2} \mathrm{O}_{5}$ contents and constant $\mathrm{PbO}$ contents, in the temperature range 150$300 \mathrm{~K}$ at four different ultrasonic frequencies. Variations of glass composition in the study of ultrasonic relaxation will throw more light on the strength and binding of these glass network structures with replacement of $\mathrm{TeO}_{2}$ by $\mathrm{Nb}_{2} \mathrm{O}_{5}$.

\section{Experimental}

\subsection{Preparation of glasses}

Three glass series $x \mathrm{Nb}_{2} \mathrm{O}_{5}-(1-x) \mathrm{TeO}_{2}, 0.1 \mathrm{PbO}-x \mathrm{Nb}_{2} \mathrm{O}_{5}$ $-(0.9-x) \mathrm{TeO}_{2}$ and $0.2 \mathrm{PbO}-x \mathrm{Nb}_{2} \mathrm{O}_{5}-(0.8-x) \mathrm{TeO}_{2}$ with 
different $\mathrm{Nb}_{2} \mathrm{O}_{5}$ contents and constant $\mathrm{PbO}$ contents have been prepared using the rapid quenching method. Chemical constituents of each glass composition are listed in table 1.

Each mixture was preheated at $673 \mathrm{~K}$ for $60 \mathrm{~min}$ to remove $\mathrm{H}_{2} \mathrm{O}$ and $\mathrm{CO}_{2}$. Then, the preheated mixture was melted in a muffle furnace, whose temperature was controlled at $1173 \mathrm{~K}$

Table 1. Glass compositions.

\begin{tabular}{lll}
\hline & Glass composition $(\mathrm{mol} \%)$ & \\
\hline $\mathrm{TeO}_{2}$ & $\mathrm{Nb}_{2} \mathrm{O}_{5}$ & $\mathrm{PbO}$ \\
\hline 0.95 & 0.05 & - \\
0.9 & 0.1 & - \\
0.85 & 0.15 & - \\
0.8 & 0.2 & - \\
0.9 & 0 & 0.1 \\
0.85 & 0.05 & 0.1 \\
0.8 & 0.1 & 0.1 \\
0.7 & 0.2 & 0.1 \\
0.8 & 0 & 0.2 \\
0.7 & 0.1 & 0.2 \\
0.6 & 0.2 & 0.2 \\
\hline
\end{tabular}

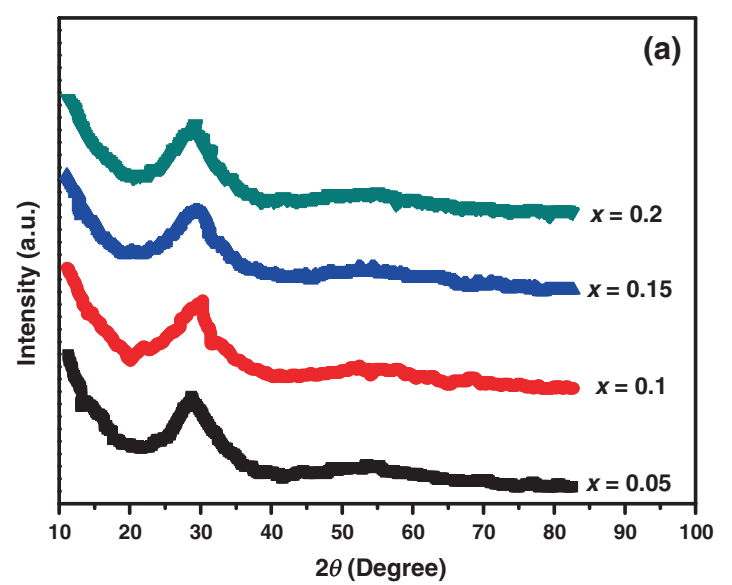

for $60 \mathrm{~min}$. Homogeneous mixture was obtained by intermediate stirring. The molten mixture was then poured in a mold made of mild steel, which had been preheated at about $575 \mathrm{~K}$. Annealing was performed for a period of $60 \mathrm{~min}$ at $723 \mathrm{~K}$. Bulk glass samples of about $1 \times 1 \times 4 \mathrm{~cm}^{3}$ were therefore obtained. It was then polished with fine alumina abrasive and machine oil on a glass plate. The deviation in the thickness of the sample was found to be $\pm 20 \mu \mathrm{m}$. The amorphous nature in all glass series was confirmed using X-ray diffraction (XRD), as shown in figure 1.

\subsection{Density measurements}

The density values $(\rho)$ of all glass compositions were determined employing Archimedes principle using toluene. The experiment was repeated three times and the error in density measurement in all glass samples was $\pm 0.005 \mathrm{~g} \mathrm{~cm}^{-3}$.

\subsection{Ultrasonic attenuation measurements}

A cryostatic setup with liquid air as cryogen was used to set the sample at the desired temperature between that of liquid

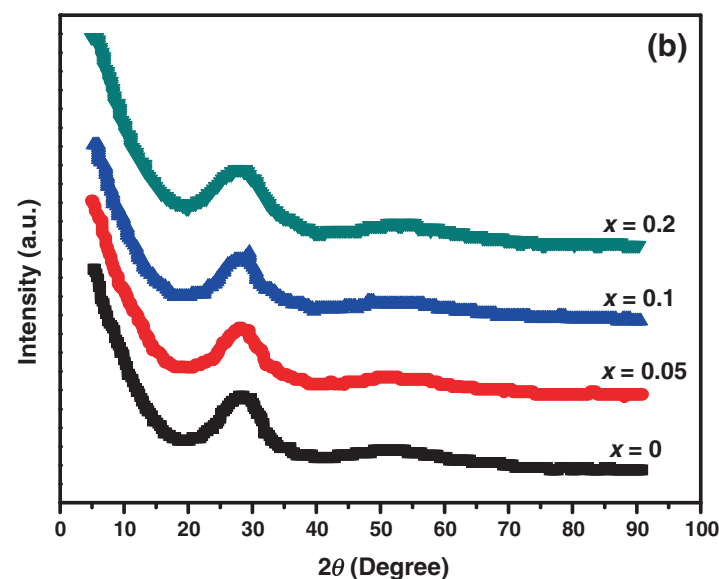

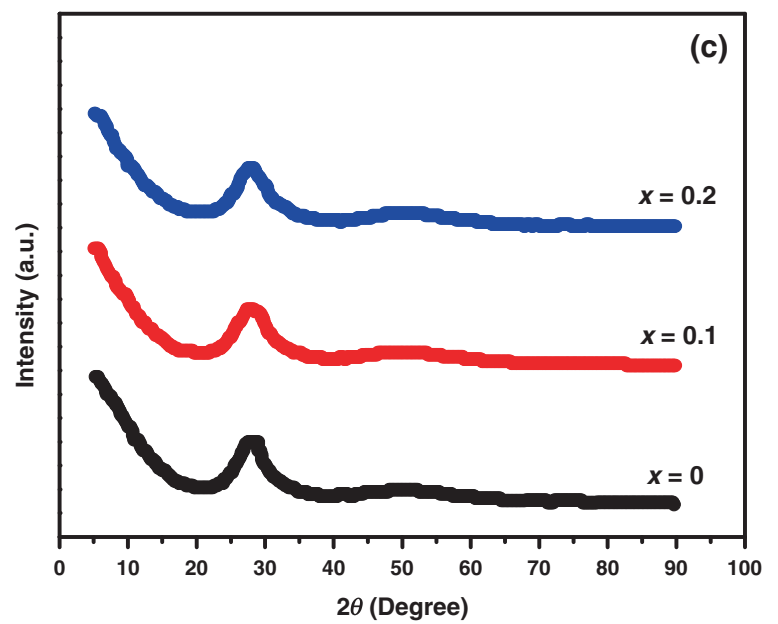

Figure 1. X-ray diffraction patterns for: (a) $x \mathrm{Nb}_{2} \mathrm{O}_{5}-(1-x) \mathrm{TeO}_{2}$, (b) $0.1 \mathrm{PbO}-x \mathrm{Nb}_{2} \mathrm{O}_{5}-(0.9-x) \mathrm{TeO}_{2}$ and (c) $0.2 \mathrm{PbO}-x \mathrm{Nb}_{2} \mathrm{O}_{5}-(0.8-x) \mathrm{TeO}_{2}$ tellurite glass systems. 
air and room temperature. The glass sample with the bonded transducer (nonak-stopcock grease, which proved to be satisfactory couplant) was placed in a suitable holder and placed inside the cooled chamber. A thermocouple was placed in direct contact with the sample in order for the temperature of the sample to be measured.

Measurements of ultrasonic attenuation were performed using an ultrasonic flaw detector USIP 20 (KrautkramerGermany). The method used in this study was the pulse echo technique, where only one transducer acted as transmitter and receiver simultaneously. Experiment was carried out in the temperature range from 150 to $300 \mathrm{~K}$ and at four ultrasonic frequencies namely; 2, 4, 6 and $8 \mathrm{MHz}$. Heights of two successive echoes were measured and then the attenuation coefficient was calculated using the following equation:

$$
\alpha=\frac{20}{2 d} \log \left(\frac{A_{1}}{A_{2}}\right),
$$

where $d$ is the thickness of the sample, $A_{1}$ and $A_{2}$ the heights of the first and second echo, respectively, which represent the amplitudes of the two echoes.

\section{Results and discussion}

\subsection{Density and molar volume}

Density is one of the powerful tools for describing the changes in the structure of glasses. It is greatly affected by structural softening or compactness, change in the geometrical configuration, coordination number, crosslink density and dimension of the interstitial spaces of the glass network structure.

Table 2 shows the mol\% content for each constituent oxide in the studied glass compositions, their density values and molar volume, while figure 2 shows the variation of density with incorporation of different $\mathrm{Nb}_{2} \mathrm{O}_{5}$ mol\% contents at the expense of $\mathrm{TeO}_{2}$ while the contents of $\mathrm{PbO}$ are constants. It is clear from table 2 and figure 2 that, the increase in $\mathrm{Nb}_{2} \mathrm{O}_{5}$ mol\% content resulted in the decrease in density values. The decrease in density values with the addition of $\mathrm{Nb}_{2} \mathrm{O}_{5}$ was expected due to the fact that the density of $\mathrm{Nb}_{2} \mathrm{O}_{5}$ is $4.600 \mathrm{~g} \mathrm{~cm}^{-3}$, which is much lower than $\mathrm{TeO}_{2}\left(5.900 \mathrm{~g} \mathrm{~cm}^{-3}\right)$ and $\mathrm{PbO}\left(9.350 \mathrm{~g} \mathrm{~cm}^{-3}\right) .{ }^{9}$ As reported by Komatsu et al, ${ }^{10}$ the structural unit of $\mathrm{TeO}_{2}$-based glasses changes gradually from asymmetrical $\mathrm{TeO}_{4}$ trigonal bipyramid (tbps) to $\mathrm{TeO}_{3}$ trigonal pyramid (tps) accompanied with increasing amounts of other components such as alkali and alkali earth elements.

Moreover, the values of molar volume $\left(V_{\mathrm{a}}\right)$ were found to increase with increasing $\mathrm{Nb}_{2} \mathrm{O}_{5}$ contents as shown in figure 3. This increase was expected as the atomic radii of tellurium, niobium and lead atoms are 1.38, 1.64 and $1.46 \AA$, respectively. It is well known that, the increase in molar volume indicates the increase of voids in the glass network structure. Thus, the molar volume increase with the increasing modifier $\mathrm{Nb}_{2} \mathrm{O}_{5}$ content means the transformation of $\mathrm{TeO}_{4}$ trigonal bipyramids to $\mathrm{TeO}_{3}$ trigonal pyramids with non-bridging oxygen atoms, which indicates that the structure becomes more open.

\subsection{Ultrasonic studies}

The compositional dependence of $U_{1}$ and $K_{\mathrm{e}}$ are shown in table 2 , indicating the variation of longitudinal ultrasonic wave velocities and bulk modulus with $\mathrm{Nb}_{2} \mathrm{O}_{5}$ contents. As shown in table 2 , both $U_{1}$ and $K_{\mathrm{e}}$ increase with the increase of $\mathrm{Nb}_{2} \mathrm{O}_{5}$ concentration over the entire three glass compositions studied. The behaviours of ultrasound wave velocities and elastic moduli were understood on the basis of the structural changes of tellurite glass network. As reported before by Lin et $\mathrm{l}^{11}$ the network structure of the $\mathrm{TeO}_{2}-\mathrm{Nb}_{2} \mathrm{O}_{5}$ glasses was modified by the $\mathrm{Nb}^{5+}$ ions. At lower contents of $\mathrm{Nb}_{2} \mathrm{O}_{5}$, most of $\mathrm{Te}^{4+}$ ions exist as $\left[\mathrm{TeO}_{4}\right]$ tbps and form $\mathrm{Te}-\mathrm{O}$ chains, the $\left[\mathrm{TeO}_{4}\right]$ tbps link each other by both apical sharing and edge sharing, while a few of $\left[\mathrm{TeO}_{3}\right]$ bps exist in the glass network. The $\mathrm{Nb}^{5+}$ ions were found to exist as $\left[\mathrm{NbO}_{6}\right]$ octahedra to link the chains as shown in figure 4. Insufficient linkages of the $\mathrm{Te}-\mathrm{O}$ chains were found due to insufficient amount of $\mathrm{Nb}^{5+}$ ions in the $\mathrm{TeO}_{2}-\mathrm{Nb}_{2} \mathrm{O}_{5}$ glass structures, indicating that the glass network easily loses its stability. Therefore, the metastable edge-sharing $\left[\mathrm{TeO}_{4}\right]$ tbps will first form edge-sharing $\beta-\mathrm{TeO}_{2}$ phase at lower temperature. The apicalsharing $\left[\mathrm{TeO}_{4}\right]$ tbps are more stable than the edgesharing ones, they will form $\alpha-\mathrm{TeO}_{2}$ phase with similar structure at higher temperatures. Te-O chains connected with $\mathrm{Nb}^{5+}$ ions are more stable, they will form $\mathrm{Te}_{3} \mathrm{Nb}_{2} \mathrm{O}_{11}$ phase with apical sharing structure at much higher temperatures. ${ }^{12}$ At higher contents of the modifier $\mathrm{Nb}_{2} \mathrm{O}_{5}$ in the glass structure, more and more $\mathrm{Nb}^{5+}$ ions will connect $\mathrm{Te}-\mathrm{O}$ chains as $\left[\mathrm{NbO}_{6}\right]$ octahedra, just like the $\left[\mathrm{NbO}_{6}\right]$ octahedral chain between $\left[\mathrm{TeO}_{4}\right]$ tbp chains in the $\mathrm{Nb}_{2} \mathrm{Te}_{4} \mathrm{O}_{13}$ crystal, in which some of the polyhedra are linked by edge sharing. ${ }^{13}$ The modifier $\mathrm{Nb}_{2} \mathrm{O}_{5}$ will provide oxygen ions to transform more $\left[\mathrm{TeO}_{4}\right]$ tbps into $\left[\mathrm{TeO}_{3}\right]$ bps. The glass network is strengthened by enhancing the linkage of $\mathrm{Te}-\mathrm{O}$ chains. Moreover, the tellurite network will come to homogenization, because of the uniform distribution of $\mathrm{Nb}^{5+}$ ions among the $\mathrm{Te}-\mathrm{O}$ chains, although some of the tellurium-oxide polyhedra still link each other in edge sharing. These results give the reason for the increase in the dissociation energy $(\mathrm{Gi})$, which was calculated according to Makishima and Mackenzie model ${ }^{14,15}$ as shown in table 2. Therefore, the increase in bulk modulus was suggested as due to the incorporation of $\mathrm{Nb}_{2} \mathrm{O}_{5}$ contents with bond energy of $\mathrm{Nb}-\mathrm{O}$ bond $\left(\sim 771 \mathrm{~kJ} \mathrm{~mol}^{-1}\right)$, which is higher than the bond energy of $\mathrm{Pb}-\mathrm{O}\left(\sim 382 \mathrm{~kJ} \mathrm{~mol}^{-1}\right)$ and Te-O bonds $\left(\sim 376 \mathrm{~kJ} \mathrm{~mol}^{-1}\right){ }^{9}$

The variations of ultrasonic attenuation coefficient for longitudinal ultrasonic waves with temperature at four operating frequencies 2, 4, 6 and $8 \mathrm{MHz}$ for the three glass compositions $0.95 \mathrm{TeO}_{2}-0.05 \mathrm{Nb}_{2} \mathrm{O}_{5}, 0.85 \mathrm{TeO}_{2}-0.05 \mathrm{Nb}_{2} \mathrm{O}_{5}-$ $0.1 \mathrm{PbO}$ and $0.7 \mathrm{TeO}_{2}-0.1 \mathrm{Nb}_{2} \mathrm{O}_{5}-0.2 \mathrm{PbO}$ are shown in figures 5-7, respectively. All plots for the other glass compositions showed the same behaviour as that shown in figures 5-7. A well-defined broad peaks are observed at 


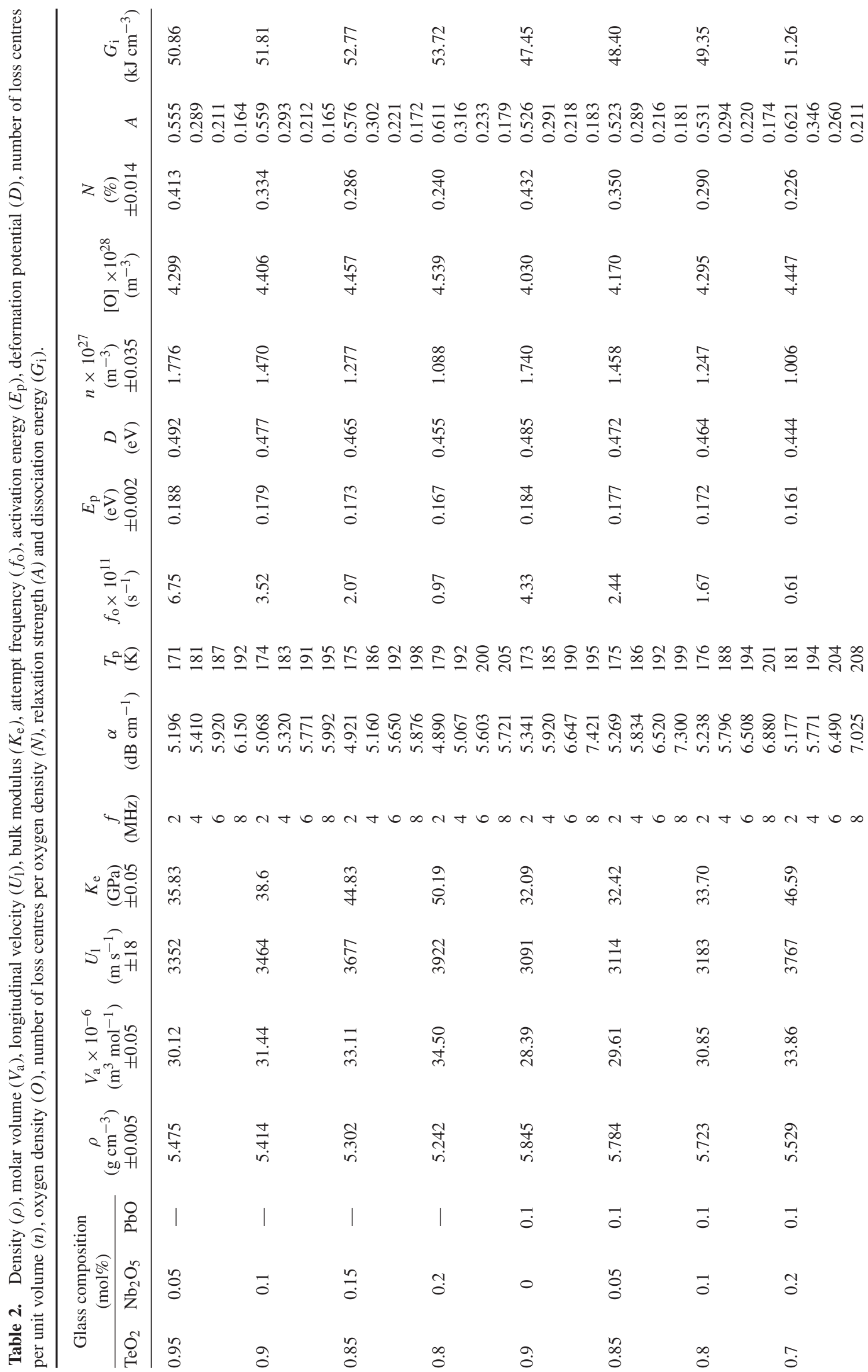




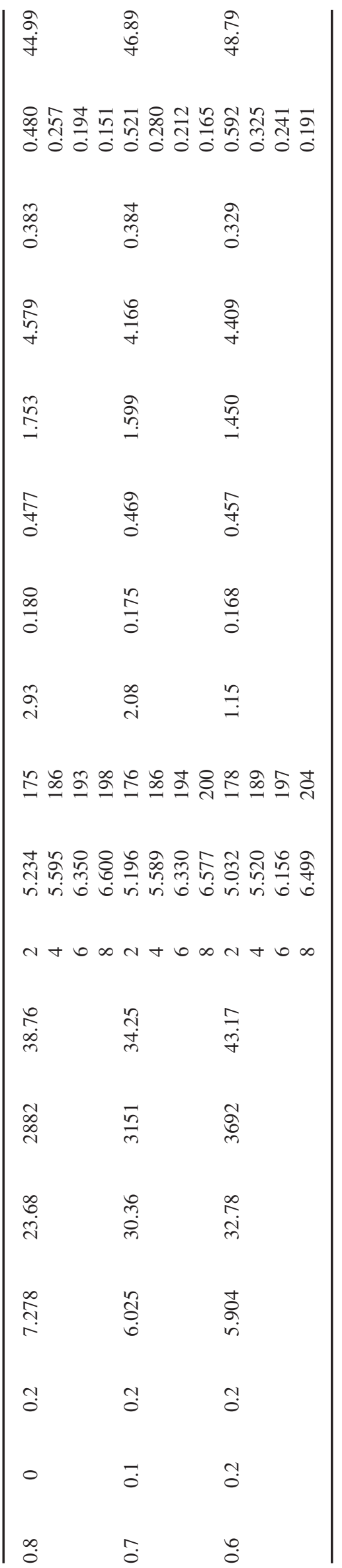

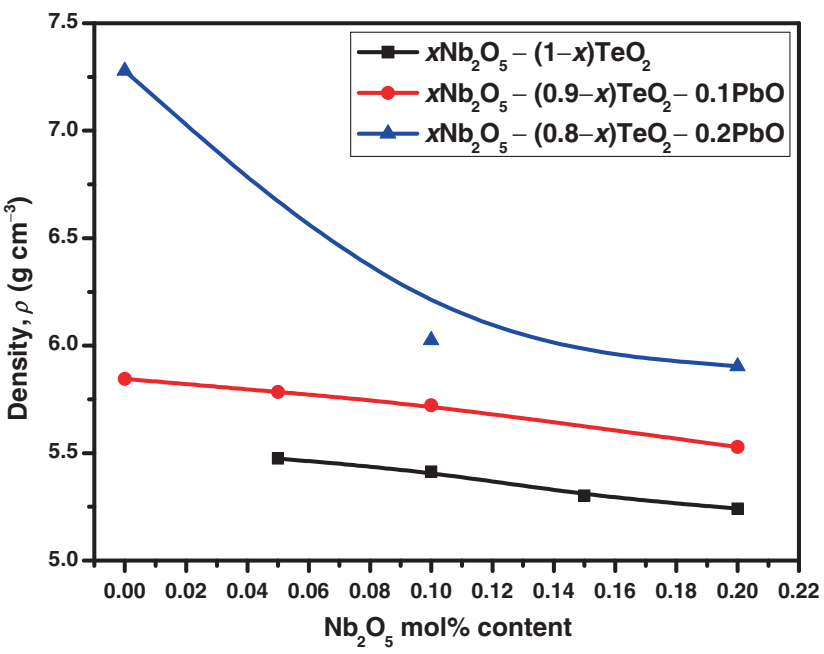

Figure 2. Variation of density of the three investigated glass series with $\mathrm{Nb}_{2} \mathrm{O}_{5}$ mol\% content.

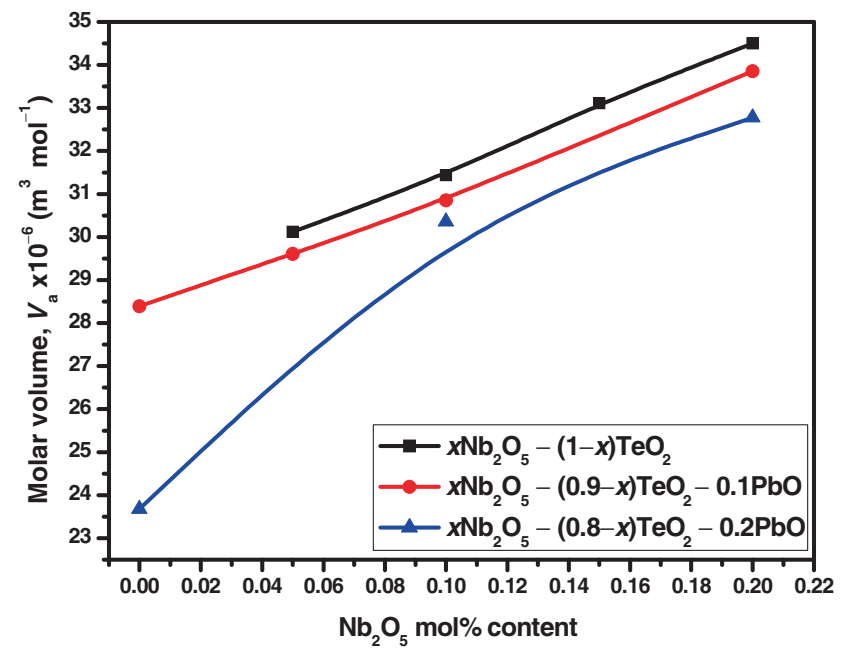

Figure 3. Variation of molar volume of the four investigated glass series with $\mathrm{Nb}_{2} \mathrm{O}_{5} \mathrm{~mol} \%$ content.

a temperatures in the range from 150 to $300 \mathrm{~K}$ depending on the compositions of the glass structures. Also, it is clear from these figures that, with the increase in operating frequency the temperature peak shifts slowly to the higher temperatures, and the height of this maximum increases linearly.

Moreover, it can be observed from these figures that the temperature peak position shifts to higher temperature as the $\mathrm{Nb}_{2} \mathrm{O}_{5}$ modifier mol\% content increased. Furthermore, the tails of the loss curves overlap each others, which is mainly due to the thermal broadening as the operating frequency is increased.

Figures 8-10 show the relations between the inverse of the temperature peaks and the operating frequencies for all glass compositions. All plots yielded straight lines, 

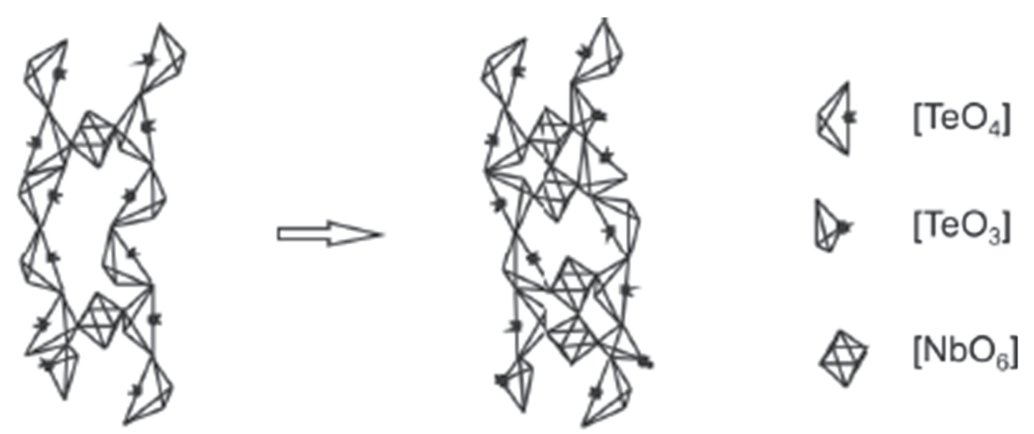

\section{Lower $\mathrm{Nb}^{5+}$ content}

\section{Higher $\mathrm{Nb}^{5+}$ content}

Figure 4. Schematic diagram of the $\mathrm{TeO}_{2}$ glass network modified by $\mathrm{Nb}_{2} \mathrm{O}_{5}$ as a network modifier.

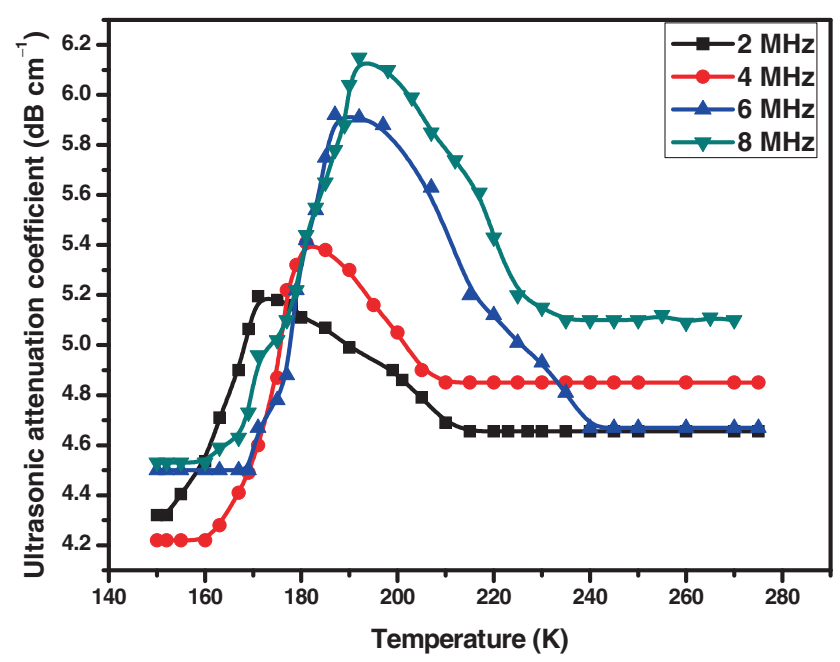

Figure 5. Variation of ultrasonic attenuation coefficient glass composition $0.95 \mathrm{TeO}_{2}-0.05 \mathrm{Nb}_{2} \mathrm{O}_{5}$.

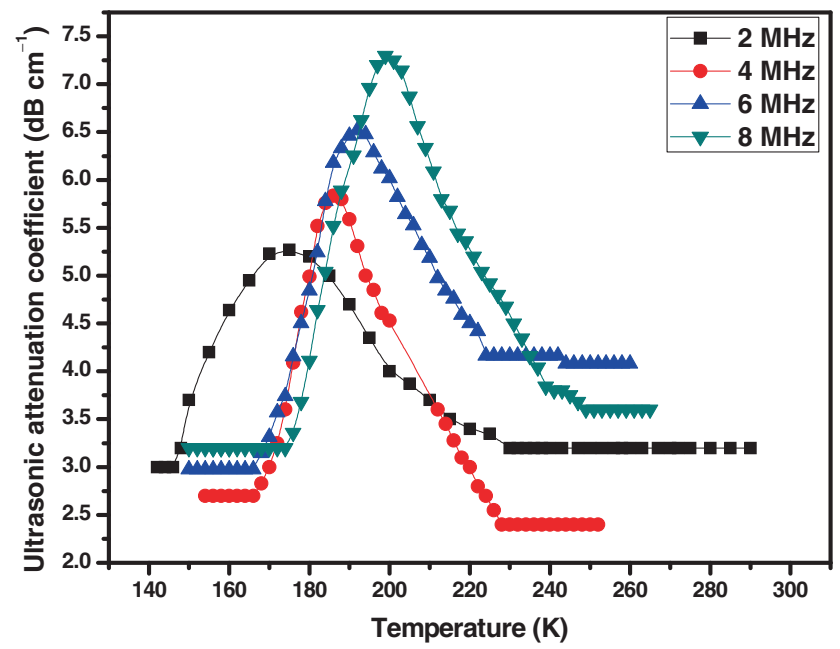

Figure 6. Variation of ultrasonic attenuation coefficient glass composition $0.85 \mathrm{TeO}_{2}-0.05 \mathrm{Nb}_{2} \mathrm{O}_{5}-0.1 \mathrm{PbO}$.

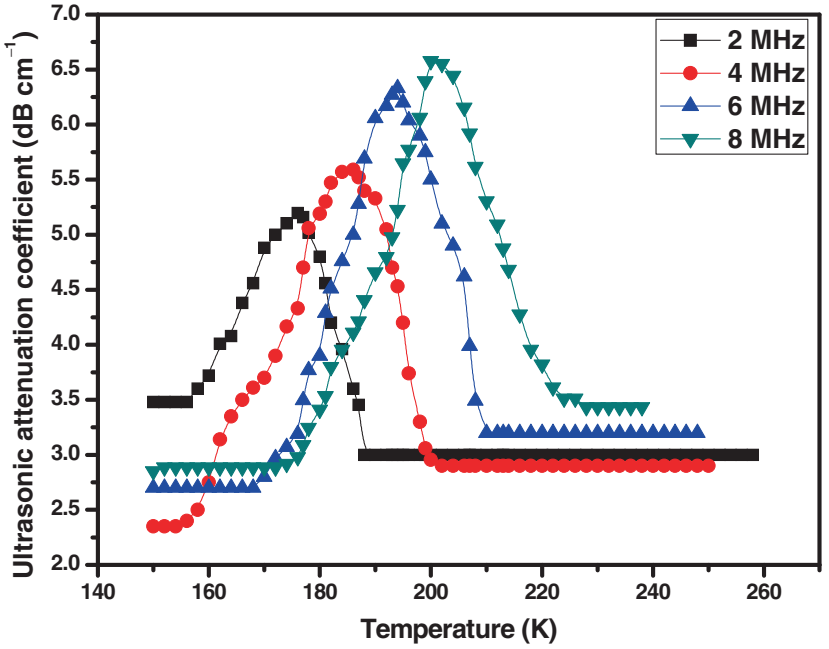

Figure 7. Variation of ultrasonic attenuation coefficient for glass composition $0.70 \mathrm{TeO}_{2}-0.10 \mathrm{Nb}_{2} \mathrm{O}_{5}-0.20 \mathrm{PbO}$.

indicating that for a given glass composition, the peak fit an equation of the form

$$
f=f_{\mathrm{o}} \exp -\frac{E_{\mathrm{p}}}{K T_{\mathrm{p}}}
$$

where $f_{\mathrm{o}}$ and $E_{\mathrm{p}}$ are the classical vibration frequency (attempt frequency) and activation energy, respectively, which were obtained from the intercept and the slope of the lines (figures 8-10). Figures 5-7 together with figures 8-10 suggest that some sort of relaxation process is operative. Values of the ultrasonic attenuation, peak temperature, classical attempt frequency and activation energy of the relaxation process are given in table 2 . The values of $E_{\mathrm{p}}$ were found to decrease with the increase in $\mathrm{Nb}_{2} \mathrm{O}_{5}$ modifier content for the three glass series (as shown in figure 11), $x \mathrm{Nb}_{2} \mathrm{O}_{5}-(1-x) \mathrm{TeO}_{2}, 0.1 \mathrm{PbO}-x \mathrm{Nb}_{2} \mathrm{O}_{5}-(0.9-x) \mathrm{TeO}_{2}$ and $0.2 \mathrm{PbO}-x \mathrm{Nb}_{2} \mathrm{O}_{5}-(0.8-x) \mathrm{TeO}_{2}$.

The reason for the absorption loss was suggested as due to a thermally activated particle, and the relaxation process 


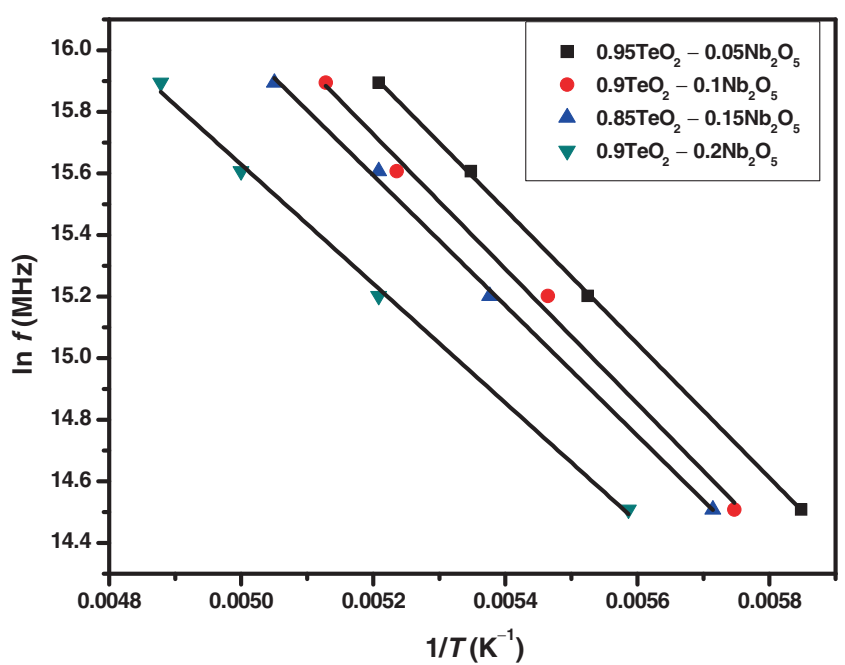

Figure 8. Relation between logarithm of operating frequency and inverse of temperature peak for the binary $(1-x) \mathrm{TeO}_{2}-x \mathrm{Nb}_{2} \mathrm{O}_{5}$ glass system.

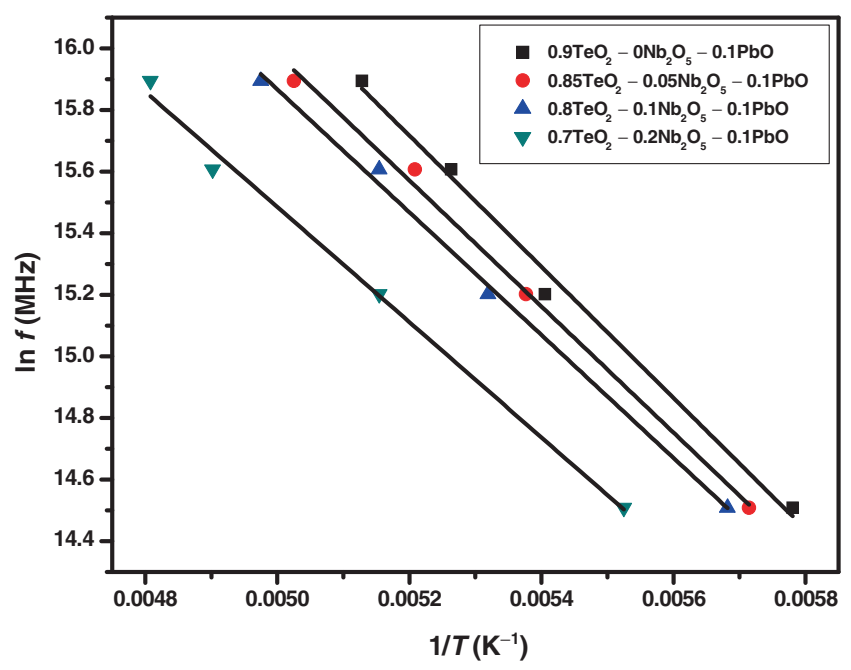

Figure 9. Relation between logarithm of operating frequency and inverse of temperature peak for the binary $(0.9-x) \mathrm{TeO}_{2}-$ $x \mathrm{Nb}_{2} \mathrm{O}_{5}-0.1 \mathrm{PbO}$ glass system.

can be described as due to a particle moving in an asymmetric double-well potential of atomic dimension. This particle motion can be understood as an oscillation around either of two-well potential minima. The ultrasonic waves disturb the equilibrium and resulted in a relative energy shift between the minima of the double wells by an amount $\Delta E=D \varepsilon$, where $D$ is the deformation potential that shows the energy shift of the relaxing states in a strain field of unit strength and $\varepsilon$ is the magnitude of the strain field. Thus, the deformation potential is given by Gaafar and Sidkey ${ }^{7}$ in the form

$$
D=1.5 E_{\mathrm{p}}^{2 / 3} \text {. }
$$

The variation of the values of deformation potential $(D)$ for the three glass series investigated are given in table 2 . It

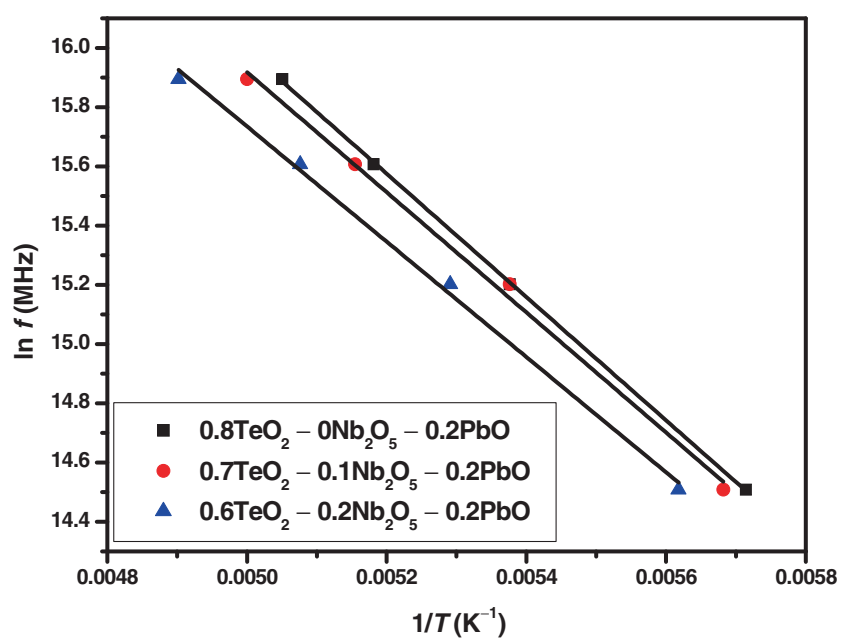

Figure 10. Relation between logarithm of operating frequency and inverse of temperature peak for the binary $(0.8-x) \mathrm{TeO}_{2}-$ $x \mathrm{Nb}_{2} \mathrm{O}_{5}-0.2 \mathrm{PbO}$ glass system.

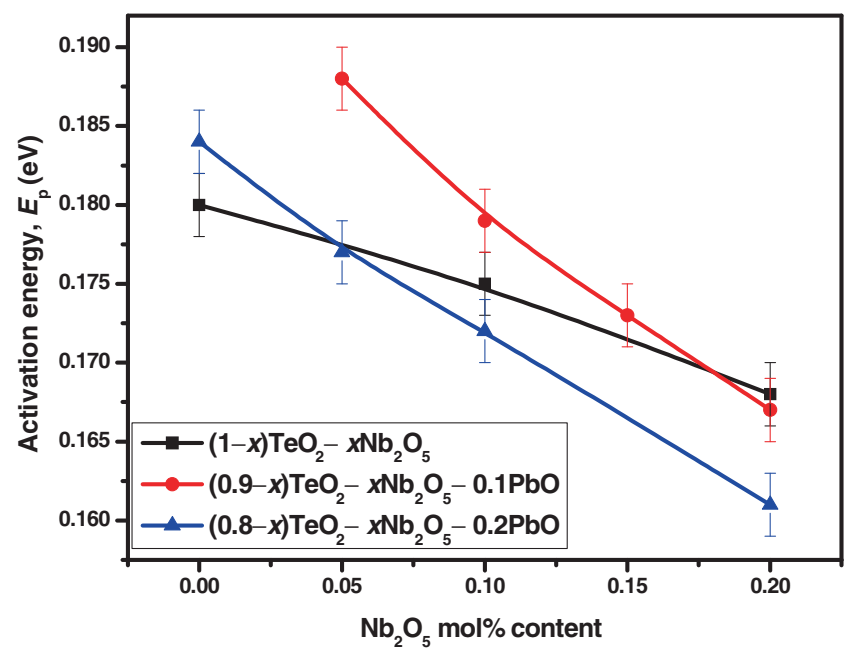

Figure 11. Variation of activation energy for glass systems $x \mathrm{Nb}_{2}$ $\mathrm{O}_{5}-(1-x) \mathrm{TeO}_{2}, 0.1 \mathrm{PbO}-x \mathrm{Nb}_{2} \mathrm{O}_{5}-(0.9-x) \mathrm{TeO}_{2}$ and $0.2 \mathrm{PbO}-x$ $\mathrm{Nb}_{2} \mathrm{O}_{5}-(0.8-x) \mathrm{TeO}_{2}$.

can be seen that the deformation potential decreases with the increase of $\mathrm{Nb}_{2} \mathrm{O}_{5}$ modifier mol\% content.

Therefore, the ultrasonic waves resulted in a thermal inequilibrium and the relaxation process is setup to restore the equilibrium again. The particle can overcome the barrier between the double wells in a thermally activated process. Moreover, the width of the temperature peaks indicates that a single relaxation process with $\tau=\tau_{\mathrm{o}} \exp \left(E_{\mathrm{p}} / K T_{\mathrm{p}}\right)$ makes this relation as unsuitable for description. Furthermore, the activation energies, $E_{\mathrm{p}}$, obtained in this study (table 2) are spread of values around a fixed value obtained in crystalline $x \mathrm{Nb}_{2} \mathrm{O}_{5}-(1-x) \mathrm{TeO}_{2}, 0.1 \mathrm{PbO}-x \mathrm{Nb}_{2} \mathrm{O}_{5}-(0.9-x) \mathrm{TeO}_{2}$ and $0.2 \mathrm{PbO}-x \mathrm{Nb}_{2} \mathrm{O}_{5}-(0.8-x) \mathrm{TeO}_{2}$ glasses, i.e., some kind of average over a broad distribution of activation energies. Thus, the loss peaks have to be described in terms of the distribution of relaxation times with each relaxing particle 
moving in the double-well potential. ${ }^{16}$ Also, for a system of $(n)$ particles per unit volume moving in identical doublewell potentials of barrier height (see figure 12), the internal friction is given by the equation

$$
\begin{aligned}
Q^{-1}= & \frac{2 \alpha V}{\omega} \\
= & \frac{n D^{2}}{\rho V^{2}} \frac{\mathrm{d}}{\mathrm{d} \Delta}\left(\frac{1}{1+e^{\Delta / K T}}\right) \frac{\omega \tau}{1+\omega^{2} \tau^{2}} \\
= & \frac{D^{2}}{\rho V^{2}} \int_{0}^{\infty} \int_{0}^{\infty} \frac{\mathrm{d}}{\mathrm{d} \Delta}\left(\frac{1}{1+e^{\Delta / k T}}\right) X \frac{\omega \tau}{1+\omega^{2} \tau^{2}} \\
& \quad \times n(\Delta) n(E) \mathrm{d} \Delta \mathrm{d} E,
\end{aligned}
$$

where

$$
\tau=\tau_{\mathrm{o}} e^{E / K T}\left(1+e^{-\Delta / K T}\right),
$$

where $K$ is Boltzmann's constant, $T$ the absolute temperature, $\alpha$ the ultrasonic absorption coefficient in Nepers per unit length, $\omega$ is the angular frequency, $V$ the phase velocity, $\tau$ the relaxation time, $\tau_{\mathrm{o}}^{-1}$ the attempt frequency for the particle in either well, $\Delta$ the free-energy difference between corresponding particle states in the two wells, i.e., the separation of the well minima, $n$ the number of loss centres and $D$ the deformation potential that represents the energy shift of the two-well states in a strain field of unit strength averaged over all possible well orientation. Thus, for the asymmetric distribution, where $\Delta \geq 2 K T$ and taking $n(\Delta)=n_{\mathrm{o}}$, equation (4) can be rewritten with a constant independent of both $\Delta$ and $E$ in the simple form

$$
Q^{-1}=\frac{2 n_{\mathrm{o}} D^{2}}{\rho V^{2}} \int_{0}^{\infty} \frac{\omega \tau n(E) \mathrm{d} E}{1+\omega^{2} \tau^{2}},
$$

where $n(E) \mathrm{d} E$ is the number of two-well systems (number of loss centres), with barrier height in the range from $E$ to $(E+\mathrm{d} E)$, which is expressed as a function of vibrating particles.

As the tellurite glass is regarded as three-dimensional network $\mathrm{A}-\mathrm{O}-\mathrm{A}(\mathrm{A}=$ cation, $\mathrm{O}=$ anion $)$ bonds, there will also

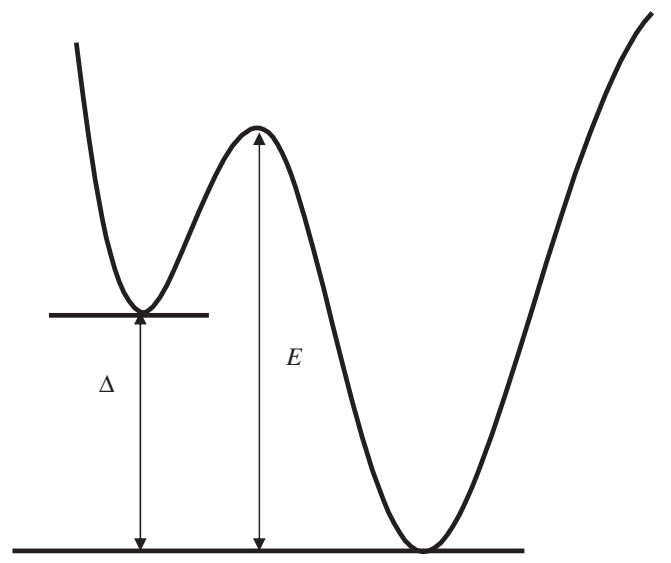

Figure 12. Double-well potential. be a distribution of both the thermally averaged cationanion-cation spacing about an equilibrium value and a corresponding distribution of (A-O-A) angles. Also, there will be always a distribution of $\mathrm{A}-\mathrm{A}$ separations (bond lengths) with values both greater or less than the equilibrium (crystalline) value. Therefore, the total number of the two-well systems per unit volume is proportional to the oxygen density. ${ }^{17}$

Considering a distribution of double-well systems of vibrating particles that will arise from the spread of cationanion spacing with a distribution of barrier heights which are proportional to the bond strength, for both longitudinal and transverse motions of the anion for all kind of bonds, and considering the motion of oxygen atoms as the most lighter vibrating particles (since tellurium, and tungsten atoms have relatively larger masses), then for any one of the double-well system A-O-A, further oxygen atoms situated to the left and the right of cation A will be situated at sites slightly at different distances from the latter. It follows that the variability of Te-O-Te, Te-O-Nb, Te-O-Pb, Nb-O-Nb, Nb-O-Pb and $\mathrm{Pb}-\mathrm{O}-\mathrm{Pb}$ bond angles means that there is a spread of the atomic ring size in the glass system under investigation. The distribution of asymmetries $\Delta$ will appear as a second-order effect. At peak temperature $T_{\mathrm{p}}$, the oxygen atoms consisted in the double-well system will change the configuration by thermal activation energy, with hopping over the barrier.

Therefore, the total number of double-well potential systems (loss centres, i.e., number of oxygen atoms that will absorb ultrasonic wave) per unit volume is given by

$$
\begin{aligned}
& n=\int_{0}^{\infty} n(E) \mathrm{d} E, \\
& n=\frac{\rho V^{2}}{2 n_{\mathrm{o}} D^{2}} \int_{0}^{\infty} c(E) \mathrm{d} E,
\end{aligned}
$$

where the integral $\int_{0}^{\infty} c(E) \mathrm{d} E$ is the area under the curve relating $\alpha$ and $T$ in figures 5-7.

Gilroy and Phillips ${ }^{16}$ have proposed that for asymmetric double-well potential $n(E)$ takes the form

$$
n(E)=\left(1 / E_{\mathrm{p}}\right) \exp \left(-E / E_{\mathrm{p}}\right) .
$$

Assuming that $n_{\mathrm{o}}=1 / E_{\mathrm{p}}$, where $E_{\mathrm{p}}$ is the activation energy, then equation (7) can take the form

$$
n=\frac{\rho V^{2} E_{\mathrm{p}}}{2 D^{2}} \int_{0}^{\infty} c(E) \mathrm{d} E .
$$

The total number of two-well systems per unit volume was calculated, shown in table 2 and figure 13.

The oxygen density [O] was also calculated for the three glass systems under investigation according to an equation ${ }^{18}$ in the form

$$
[\mathrm{O}]=\frac{C N_{\mathrm{A}}}{16 G},
$$




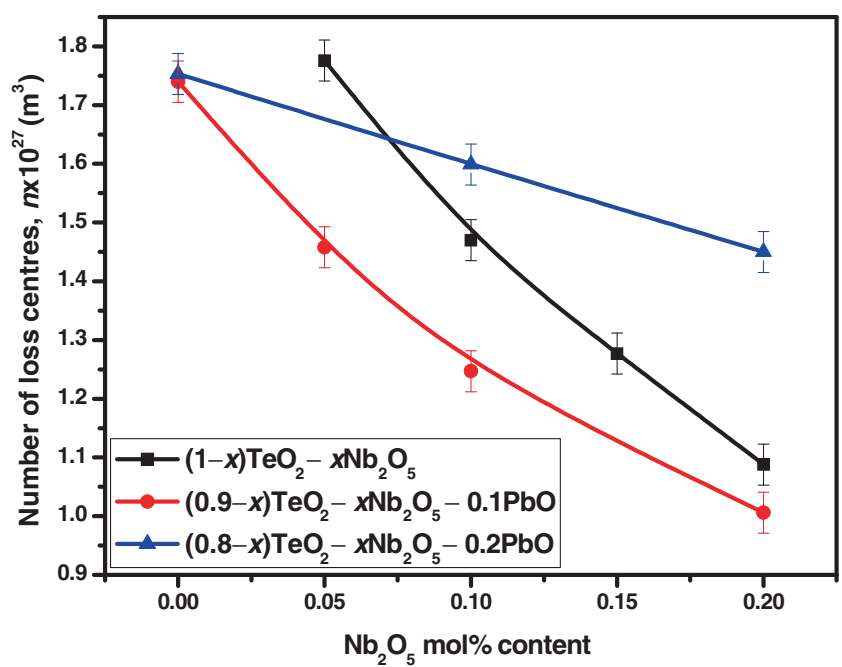

Figure 13. Variation of the loss centres per unit volume (n) for glass systems $x \mathrm{Nb}_{2} \mathrm{O}_{5}-(1-x) \mathrm{TeO}_{2}, 0.1 \mathrm{PbO}-x \mathrm{Nb}_{2} \mathrm{O}_{5}-$ $(0.9-x) \mathrm{TeO}_{2}$ and $0.2 \mathrm{PbO}-x \mathrm{Nb}_{2} \mathrm{O}_{5}-(0.8-x) \mathrm{TeO}_{2}$.

where $C$ is the total amount of oxygen in $100 \mathrm{~g}$ of the glass, $G$ the volume of $100 \mathrm{~g}$ of glass and $N_{\mathrm{A}}$ is Avogadro's number. Table 2 shows the values of the number of loss centres per unit volume, number of loss centres per oxygen atoms $N$ and oxygen density. The relaxation strength $A$ indicates the height of the internal friction peak, which in turn is a measure of the number of relaxation units exists in the glass composition and the quantity of unrelaxed strain contributed by each unit. The relaxation strength $A$ for the different glass series studied was calculated from the equation given by Carini et $a l^{19}$ as

$$
A=\frac{2 \alpha V}{\pi f},
$$

where $\alpha$ is the ultrasonic attenuation coefficient in $\mathrm{dB} \mathrm{cm}^{-1}$ (maximum relaxation loss at $T_{\mathrm{p}}$ ), $V$ the longitudinal ultrasonic velocity and $f$ the operating frequency. Table 2 shows the values of relaxation strength, which are an indication of the defect concentrations. It shows that, at the same operating frequency the relaxation strength decreases with the increase in $\mathrm{Nb}_{2} \mathrm{O}_{5}$ modifier content. Moreover, the relaxation strength decreases with the decrease in the operating frequency for the same modifier content.

Figure 14 shows the variation of the number of loss centres per oxygen atom $N$ with $\mathrm{Nb}_{2} \mathrm{O}_{5}$ modifier content. It is evident from this figure that the increase in $\mathrm{Nb}_{2} \mathrm{O}_{5}$ modifier content resulted in a decrease in the number of two-well systems per oxygen atom (number of vibrating atoms), an increase in the relaxation strength, a decrease in the deformation potential and the increase in the values of oxygen density due to the replacement of $\mathrm{TeO}_{2}$ (with coordination number 3 or 4) by $\mathrm{Nb}_{2} \mathrm{O}_{5}$ (with octahedral coordination number), thus activation energy of the relaxation process is decreased with the increase in crosslink density, which can be explained by taking into account two factors. First, the increase in the uniform

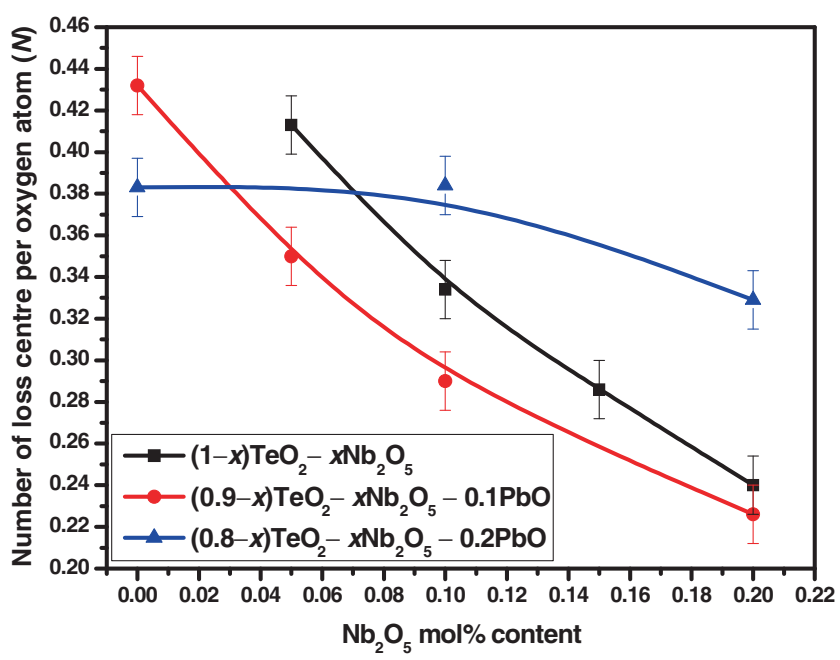

Figure 14. Variation of the loss centres per oxygen atom $(N)$ for glass systems $x \mathrm{Nb}_{2} \mathrm{O}_{5}-(1-x) \mathrm{TeO}_{2}, 0.1 \mathrm{PbO}-x \mathrm{Nb}_{2} \mathrm{O}_{5}$ $-(0.9-x) \mathrm{TeO}_{2}$ and $0.2 \mathrm{PbO}-x \mathrm{Nb}_{2} \mathrm{O}_{5}-(0.8-x) \mathrm{TeO}_{2}$.

distribution of $\mathrm{Nb}^{5+}$ ions among the $\mathrm{Te}-\mathrm{O}$ chains and consequently the increase in the crosslink density of the glass network structure. Second, the increase in the relative strength of bonds, ${ }^{8}$ which consequently means the decrease in the number of two-well systems per oxygen atom (number of vibrating atoms).

\section{Conclusions}

It can be concluded that, the longitudinal ultrasonic absorption at low temperatures showed the presence of well-defined peaks whose heights increase as the applied frequency increases. Those peaks were attributed to a thermally activated relaxation governed by the Arrhenius relationship. Also, the peak temperature was found to increase as the $\mathrm{Nb}_{2} \mathrm{O}_{5}$ content increases. The activation energy and the attempt frequency were found to decrease with the increase in $\mathrm{Nb}_{2} \mathrm{O}_{5}$ content in the three glass systems investigated.

The number of loss centres was found to be decreased with the decrease in activation energy, due to the decrease in the area under the curve of the longitudinal ultrasonic absorption $v s$. temperature as the $\mathrm{Nb}_{2} \mathrm{O}_{5}$ increases.

\section{Acknowledgement}

We would like to express our sincere thanks to the Deanship of scientific research at Majmaah University, KSA, for funding this search work under the project no. 9.

\section{References}

1. Sekiya T, Mochida N and Ohtsuka A 1992 J. Non-Cryst. Solids 144128 
2. Tatsumisago M, Minami T and Kowada Y 1994 Phys. Chem. Glasses 3589

3. Chowdari B and Kumari P 1996 J. Non-Cryst. Solids 19731

4. Pan A and Ghosh A 1999 Phys. Rev. B 603224

5. Sakata H, Sega K and Chaudhuri B 1999 Phys. Rev. B 603230

6. Jha A, Shen S and Naftaly M 2000 Phys. Rev. B 626215

7. Gaafar M S and Sidkey M A 2004 Phys. Chem. Glasses-Eur. J. Glass Sci. Technol. Part B 457

8. Gaafar M S, Abdeen Mostafa A M and Marzouk S Y 2011 J. Alloys Compd. $\mathbf{5 0 9} 3566$

9. Lid D R 2000 CRC handbook of chemistry and physics, 80th ed (London: CRC Press)

10. Komatsu T, Tawarayama H, Mohri H and Matusita K 1991 J. Non-Cryst. Solids 135105
11. Lin J, Huang W, Bian L, Ma Q, Qin S, Wei H and Chen J 2009 Mater. Sci.-Poland 27329

12. Galy J and Lindqvist O 1979 J. Solid State Chem. 27279

13. Blanchandin S, Champarnaud-Mesjard J C and Thomas P 2000 J. Alloys Compd. 306175

14. Makishima A and Mackenzie J D 1973 J. Non-Cryst. Solids 1235

15. Makishima A and Mackenzie J D 1975 J. Non-Cryst. Solids 17147

16. Gilroy K S and Phillips W A 1981 Philos. Mag. B 43735

17. Bridge B and Patel N D 1986 J. Mater. Sci. 213783

18. El-Mallawany R 1994 Mater. Chem. Phys. 39161

19. Carini G, Cutroni M, Federico M and Galli G 1982 Solid State Commun. 441427 